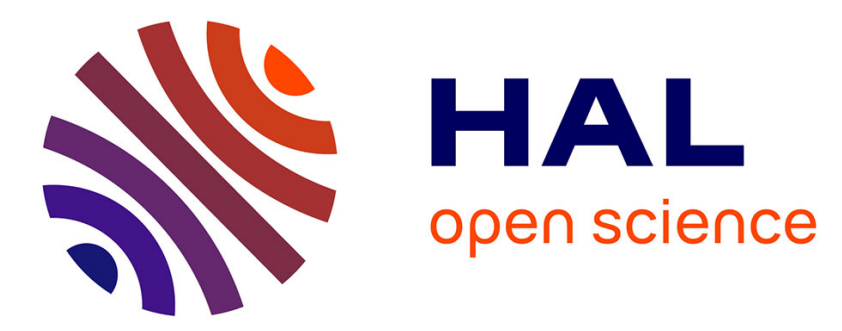

\title{
Sowing of margin strips rich in floral resources improves herbivore control in adjacent crop fields
}

\author{
Anna Pollier, Yann Tricault, Manuel Plantegenest, Armin Bischoff
}

\section{To cite this version:}

Anna Pollier, Yann Tricault, Manuel Plantegenest, Armin Bischoff. Sowing of margin strips rich in floral resources improves herbivore control in adjacent crop fields. Agricultural and Forest Entomology, 2019, 21 (1), pp.119-129. 10.1111/afe.12318 . hal-02277259

HAL Id: hal-02277259

https://institut-agro-rennes-angers.hal.science/hal-02277259

Submitted on 1 Feb 2020

HAL is a multi-disciplinary open access archive for the deposit and dissemination of scientific research documents, whether they are published or not. The documents may come from teaching and research institutions in France or abroad, or from public or private research centers.
L'archive ouverte pluridisciplinaire HAL, est destinée au dépôt et à la diffusion de documents scientifiques de niveau recherche, publiés ou non, émanant des établissements d'enseignement et de recherche français ou étrangers, des laboratoires publics ou privés. 


\title{
Sowing of margin strips rich in floral resources improves herbivore control in adjacent crop fields
}

\author{
Anna Pollier*, Yann Tricault*, Manuel Plantegenest ${ }^{\dagger}$ and Armin Bischoff \\ *UMR 1349 Institute of Genetics, Environment and Plant Protection (IGEPP), Agrocampus Ouest, 2 Rue André le Nôtre, 49045 Angers, France, \\ $\dagger$ UMR 1349 Institute of Genetics, Environment and Plant Protection (IGEPP), Agrocampus Ouest, 65 Rue de Saint-Brieuc, 35042 Rennes, France \\ and ${ }^{\ddagger}$ Mediterranean Institute of Biodiversity and Ecology (IMBE), University of Avignon, Aix-Marseille University, CNRS, IRD, IUT Agroparc, BP \\ 61207, 84911 Avignon, France
}

\begin{abstract}
Field margin vegetation provides resources for natural enemies of crop herbivores. Thus, the design of plant mixtures improving resource provisioning is being discussed increasingly with respect to improving herbivore control.

2 We set up a field experiment to assess the effect of (i) a wildflower strip optimized for nectar provisioning; (ii) a grass strip and (iii) spontaneous vegetation on herbivore regulation in oilseed rape and wheat. We also analyzed the attractiveness of plant species to natural enemies.

3 The cover of flowering entomophilous plant species as a proxy of floral resource provisioning was twice as high in wildflower strips compared with the other strip treatments. Natural enemy densities were higher within and close to wildflower strips in the field. A corresponding effect on aphid predation and aphid infestation was observed. Significant negative correlations between natural enemy abundance in the margin and aphid infestation in the fields supported a causal relationship. The sown wildflower strip species were more attractive to natural enemies than spontaneous vegetation.

4 The results of the present study demonstrate that improved nectar provisioning increased the predation and parasitism of crop herbivores. Further research on the spatio-temporal dynamics of interactions is needed to determine why not all crop herbivores respond to an increase of natural enemies in field margins.
\end{abstract}

Keywords aphids, conservation biological control, ecosystem service, natural enemies, plant-insect interactions, wildflower strips.

\section{Introduction}

The biological control of crop herbivores is an important ecosystem service provided by semi-natural habitats and related biodiversity (Fiedler et al., 2008). Such habitats provide shelter, overwintering sites and floral resources (pollen, nectar) for natural enemies of crop herbivores (Bianchi et al., 2006; Griffiths et al., 2008; Bischoff et al., 2016). Most of these habitat functions are related to the vegetation and its plant species composition. Floral resources may increase the fitness of several natural enemy groups, such as hoverflies or parasitoids (Winkler et al., 2009; Araj \& Wratten, 2015), resulting in an improvement of pest

\footnotetext{
Correspondence: Armin Bischoff. Tel.: +33 490843826; e-mail:
} armin.bischoff@univ-avignon.fr control (Blaauw \& Isaacs, 2012; Balmer et al., 2014). Predators may also benefit from feeding on alternative prey occurring on field margin plants (Balzan et al., 2014). Such an attraction and resource provisioning to natural enemies by field margin vegetation may reduce herbivore infestation and damage in adjacent crop fields. Most studies on field margin effects have focused on natural enemies (Chaplin-Kramer et al., 2011), although several studies also found a positive plant diversity effect on within field control of crop herbivores (Pfiffner \& Wyss, 2004; Dassou \& Tixier, 2016). In particular, floral resources were shown to improve and/or to reduce the crop damage caused by crop herbivores such as aphids or caterpillars (Bischoff et al., 2016).

The potential reduction of crop herbivore abundance and damage by resource provisioning for natural enemies in field margins has resulted in different approaches for improving 
regulation by conservation biological control (Landis etal., 2000; Gurr etal., 2003). The most widespread approach is the use of seed mixtures to establish wildflower strips at the field edge that provide floral resources, shelter and alternative prey for natural enemies (Pfiffner \& Wyss, 2004; Haaland et al., 2011; Tschumi etal., 2015). Many studies have confirmed that sown wildflower strips are efficient with respect to increasing the diversity and abundance of natural enemies compared with neighbouring fields. However, few studies have demonstrated a corresponding reduction of crop herbivores and their damage on crop plants (Pfiffner \& Wyss, 2004; Tschumi et al., 2015). Wildflower strips may also provide resources for pest insects and thus increase crop damage (Koji et al., 2007). Despite an insufficient knowledge of regulation efficacy, sown flower strips have been developed and implemented in agri-environment schemes of several European countries aiming to increase biodiversity of agro-ecosystems (Haaland et al., 2011).

A second common conservation biological control approach relies on the sowing of grass strips, also known as beetle banks (Collins et al., 2002; Marshall \& Moonen, 2002). Grasses are wind-pollinated and do not provide nectar, although generalist predators such as ground beetles, rove beetles and spiders may benefit from their shelter function (Collins et al., 2002). Grass strips reduce the spread of problematic weed species compared with spontaneous succession but allow the establishment of perennial herbaceous grassland vegetation (Cordeau etal., 2012), which may also contribute to crop herbivore regulation (Al Hassan etal., 2013). Because seed material comprises few species, or is even monospecific, the sowing costs are much lower than for wildflower strips. In France, sowing grass strips is mandatory at the edges of crop fields adjacent to water bodies with the aim of preventing soil erosion and water pollution by fertilizer and pesticide run-off (Cordeau et al., 2012).

In the present study, we compared three field margin types in two successive winter crops. The first margin type was a wildflower strip optimized for floral resource provisioning. The mixture comprised species producing a high quality and quantity of nectar (Hicks et al., 2016), early and late flowering species, and species with a long-lasting flowering period. Additionally, plant species providing extrafloral nectar that is easily accessible to parasitoids (Jamont et al., 2013; Heil, 2015) were included. The second margin type was a grass strip sown with two species. As a control, we used spontaneous vegetation emerging from the soil seed bank. A previous study showed that spontaneous field margins rich in insect-pollinated flowering species provide an important biological control service without the need to sow expensive seed mixtures (Bischoff et al., 2016). We focused on herbivore predation and parasitism within crop fields and correlations between field and margin strip abundance of involved arthropods. We addressed the four main questions: (i) do wildflower strips, grass strips and spontaneous vegetation differ in the attraction of natural enemies of crop herbivores; (ii) does the attraction of natural enemies by field margin vegetation increase their density in the field; (iii) do higher natural enemy densities in field margins result in higher crop herbivore predation and parasitism; and (iv) which plant species contribute to such crop herbivore regulation?

\section{Materials and methods}

\section{Study sites and experimental design}

The study sites were located in the Maine-et-Loire and Ille-et-Vilaine, two departments in Western France. We monitored two crops in rotation: oilseed rape in 2014 and wheat in 2015 , both sown as winter crops. We selected two taxonomically distant crops to evaluate whether our strip treatments have similar regulating effects on associated crop herbivores and their natural enemies. The study was set up in eight fields. The fields were the same in both years, although one field was lost in 2015. Field size was between 0.5 and 3 ha and the distance between fields was at least $3 \mathrm{~km}$. In March 2014, three strip treatments were established in the margins of each of eight oilseed rape fields: (i) a wildflower strip mixture (WS) with 30 flowering vascular plant species (see Supporting information, Table S1) optimized for the amount and period of nectar production (apart from nectar provisioning, the life cycle was considered to select plant species; annuals, biennials and perennials were included to guarantee a sufficient cover in the first and subsequent years and to avoid expensive re-sowing); (ii) a commercial grass strip mixture (GS) with the perennial grasses Lolium perenne (28\%) and Festuca arundinacea (72\%), which is a typical combination used in France to protect water bodies from pesticide and fertilizer run-off; and (iii) an unsown control strip allowing natural colonization by spontaneous vegetation (SV). The soil of all treatments was ploughed and harrowed prior to sowing. The strip area was $30 \times 3 \mathrm{~m}$ and the three treatments were randomly assigned to a field margin of $90 \mathrm{~m}$ in length for each field.

\section{Vegetation analysis}

The presence of all vascular plant species was recorded in a survey area of $20 \times 3 \mathrm{~m}$ in the centre of the margin strips. The percentage cover of each plant species was estimated visually as the vertical projection of all aboveground organs using the method of Braun-Blanquet (1964). Instead of applying estimation scales, we directly estimated cover percentage (Daamgard, 2014). At the same time, the percentage of flowering plants was evaluated for each species. Survey dates were early June 2014 for oilseed rape and late June 2015 for wheat. The total cover of flowering plants was calculated by multiplying plant cover and flowering percentage of each of the recorded plant species and summing these products across all species.

\section{Herbivores and natural enemies in field margins and crop fields}

All crop herbivores, related damage, parasitism rate and natural enemies were recorded in the margin strips and in the field at distances of $5 \mathrm{~m}$ and $30 \mathrm{~m}$ from the strips. The insect survey dates were close to the dates of the vegetation survey (0-7 days) and corresponded to peak abundance of major crop herbivores (aphids, cereal leaf beetles, weevil damage). The observation time was between $10.00 \mathrm{~h}$ and $16.00 \mathrm{~h}$ under favourable weather conditions (sunny, not windy, no rain). 
Oilseed rape was monitored in April and June 2014 at flower bud appearance and early fruiting. In each oilseed rape field and at each sampling date, 20 randomly chosen plants per distance were observed. At both survey dates, aphids (dominant species: Brevicoryne brassicae), adult parasitoids (dominant species: Diaeretiella rapae and Tersilochus heterocerus), hoverflies (Syrphidae sp., adults and larvae) and ladybugs (Coccinellidae sp., adults and larvae) were counted on each plant. In June, pod damage (yes/no) caused by fruit weevils (Ceutorhynchus assimilis) and pod midges (Dasineura brassicae) were additionally recorded on the main inflorescence. Pollen beetle (Meligethes aeneus) adults were captured and counted in April using a suction sampler (sh 86-d; Stihl, Germany). Within margin strips, all flying and easily visible insects, such as pollen beetles, adult parasitoids, ladybugs and hoverflies, were counted from outside the strip to avoid disturbance (observation time: $10 \mathrm{~min}$, at both survey dates). Afterwards, less mobile insects that were difficult to observe from outside, such as aphids (all species), hoverfly and ladybug larvae, were recorded on the plants by crossing the strips two times. Hoverfly and ladybug counts for adults and larvae were pooled for analysis. In the field margins, pollen beetles were only found at the second survey date when not occurring any more in the field. Thus, the treatment effect in margins could not be related to effects in the field.

Wheat was monitored twice in early and late June 2015 at stages of spikelet emergence and early milk ripening. In each wheat field and for each sampling date, 50 randomly chosen tillers per distance were observed. Cereal leaf beetles (Oulema sp., larvae), cereal aphids (dominant species: Sitobion avenae and Metopolophium dirhodum), aphid mummies, parasitoids, ladybugs (adults and larvae) and hoverflies (adults and larvae) were counted on each tiller. Aphid mummies indicate parasitoid attack. Aphid parasitism rate was estimated by dividing the total number of mummies at the second survey date by the sum of aphid (first date) and mummy (second date) numbers (Roschewitz etal., 2005). Within the margin strips, aphids (all species, only first survey date), parasitoids, ladybugs and hoverflies were counted at the same time as in the field. Counting method was the same as in the previous year for oilseed rape. Data from the two observation dates were pooled for analysis.

In both crops and in their margin strips, aphid predation was evaluated using bait aphids glued to sand paper (predation cards). Assuming that natural enemies and attack rates are similar to that of aphids attacking wheat and oilseed rape, we used the commercially available pea aphid Acyrthosiphon pisum as sentinel prey. Predation cards were prepared by gluing three aphids on black sandpaper sheets $(5 \times 5 \mathrm{~cm})$. The cards were attached to the leaves of oilseed rape and wheat (height $50 \mathrm{~cm}$ ), respectively. In June 2014 and 2015, we placed one card at each distance (within strips, 5 and $30 \mathrm{~m}$ ) and treatment, resulting in a total of nine cards per field and 72 (63 in 2015) cards per crop. Aphid predation was evaluated after $24 \mathrm{~h}$. An aphid was considered as predated when damaged or missing.

Under each plant carrying a predation card, we placed a pitfall trap to analyze the abundance and diversity of carnivorous ground beetles in June 2014 and 2015. Trap content was sampled 5 days after placement to identify beetles to species level.

\section{Attractiveness of margin plants}

To evaluate the role of individual plant species in crop herbivore regulation, we counted aphids and natural enemies in the margins of winter wheat fields in 2015. We first identified plant species that were visited by aphids, parasitoids, hoverflies or ladybugs. Then, we counted insect numbers on all individuals of the selected plant species in each treatment and margin strip. We did not distinguish different aphid species because we were mainly interested in alternative prey provisioning. The counts included sown and spontaneously emerging plant species to evaluate the contribution of sown wildflower strip plants to herbivore regulation.

\section{Statistical analysis}

Plant species number (richness) and cover of entomophilous (= insect-pollinated) flowering plants were analyzed as a proxy of floral resource provisioning. This proxy does not include wind-pollinated plants that only provide pollen as a floral resource but not nectar to attract insects. The biolflor database (Klotz et al., 2002) was used to identify entomophilous plants. Only species flowering at the survey date were included in this category. Herbivores, herbivore damage, natural enemies and parasitism rates were included as response variables in the analyses. With only two observations in 24 treatment $\times$ field combinations, parasitoids were too rare in wheat (2015) and had to be removed from the analyses. For response variables measured at both survey dates, we pooled the data (aphids in oilseed rape 2014, hoverflies and ladybirds in wheat 2015).

We used generalized linear models (glmer function of lme4 package in R; R Foundation for Statistical Computing, Austria) to test the strip treatment effect on plant diversity, the cover of flowering entomophilous plant species, the diversity of flowering entomophilous plant species, the number of aphids, the aphid parasitism rate, the number of natural enemies, aphid predation (predation cards) and ground beetle abundance. The basic statistical model included strip treatment as a fixed and field as a random effect. Analyses were run separately for the two crop species (wheat, oilseed rape) and the three distances $(0 \mathrm{~m}=$ within strips, 5 and $30 \mathrm{~m})$. Vegetation data and aphid parasitism were normally distributed and thus analyzed using a Gaussian distribution and identity link. For count data, we fitted a Poisson distribution with log-link function. When overdispersion was detected, models were fitted using a negative binomial error distribution. The glht function (multcomp package) was used to run multiple comparisons within significant effects.

We additionally tested correlations between field margin abundance and abundance within fields for herbivores and their natural enemies. Using generalized linear models (R MASS package; https://cran.r-project.org/web/packages/MASS), margin abundance was used as an explanatory variable and field abundance as a response variable. The distributions and link functions were the same as in the basic model.

Descriptive statistics were used to compare the attractiveness of different plant species. Insect abundance per plant species depends on the size and abundance of this particular species. To obtain information on attractiveness independent of plant size and abundance, the insect counts were standardized for plant 
2014
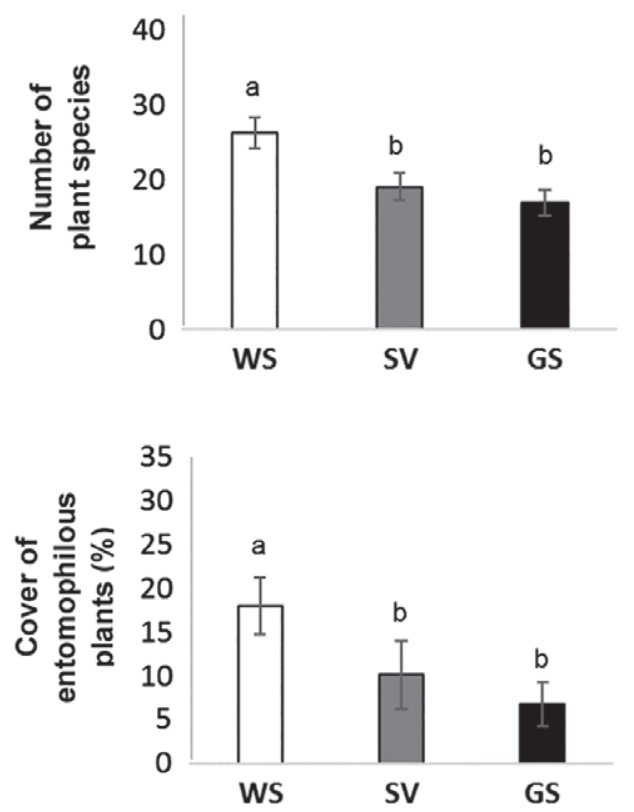
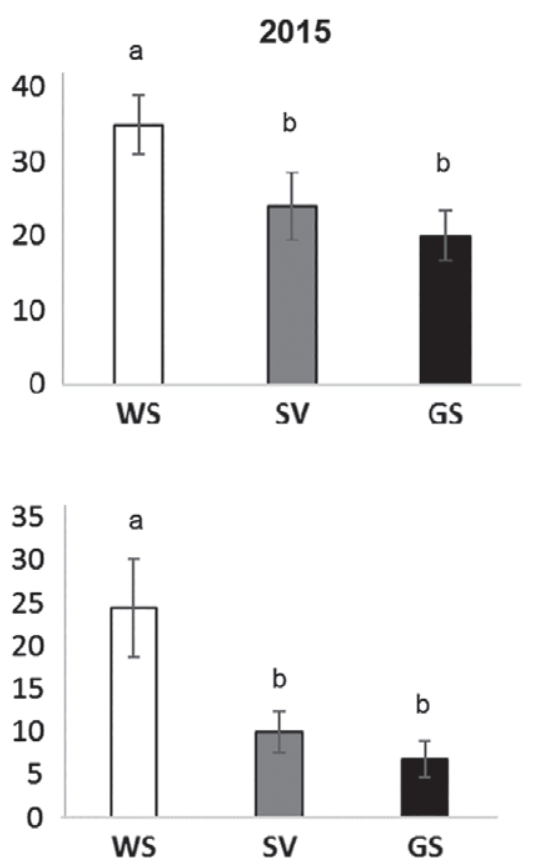

Figure 1 Mean \pm SE number of plant species and percentage cover of entomophilous plants of three field margin types in 2014 (left, oilseed rape) and 2015 (right, winter wheat). WS, wildflower strip; SV, spontaneous vegetation; GS, grass strip. $P<0.05$.

cover. In aphids, count data were divided by total plant cover; in natural enemies depending on nectar, count data were divided by flower cover (individual plant species in Table 3; whole plant community in Fig. 4). All analyses were run in R, version 03.2.2 (R Development Core Team, 2015).

\section{Results}

In both years, the number of plant species and the cover of flowering entomophilous species were significantly higher in wildflower strips than in spontaneous vegetation and in grass strips (Fig. 1). The most common spontaneously occurring plants were the grasses Avena fatua, Bromus sterilis, F. arundinacea and L. perenne, as well as the herbs Chenopodium album and Polygonum aviculare. In wildflower strips, the cover of sown species was $37.5 \%$, compared with spontaneously emerging species covering $70 \%$. The differences in species richness and the cover of entomophilous plants were not significant between spontaneous vegetation and grass strips. In wildflower strips, plant diversity and the cover of flowering entomophilous species increased from 2014 to 2015, corresponding to the development of the sown biennial and perennial species only developing and/or flowering from the second year onward. In the other strip treatments, the number of plant species increased but not the cover of flowering entomophilous species.

In oilseed rape fields, the dominant crop herbivores were pollen beetles and aphids (Fig. 2). Pollen beetle abundance was not significantly different between the strip treatments. Total aphid number including species not feeding on oilseed rape was higher in wildflower than in the other strips (Table 1). In the crop field, aphid infestation was significantly lower close to wildflower strips than close to spontaneous vegetation
(5 m) and grass strips (30 m), respectively. Aphid predation was higher in the wildflower strip and at $5 \mathrm{~m}$ compared with other treatments but differences to spontaneous vegetation were not significant (Fig. 2 and Table 1). No significant differences in aphid predation occurred at $30 \mathrm{~m}$ inside crop fields. Hoverflies were the predominant aphid predators observed in the margin strips. Hoverfly density (larvae and adults) was significantly higher in wildflower strips than in the other strips (Fig. 2). A similar difference was also observed at $5 \mathrm{~m}$ in the crop fields but not at $30 \mathrm{~m}$. Ladybug abundance (larvae and adults) was not significantly different between strip treatments (Fig. 2). Pod damage was only different at a distance of $30 \mathrm{~m}$, being higher in the wildflower strip treatment. Carnivorous ground beetles were more abundant in and close to wildflower strips $(5 \mathrm{~m})$ but, at $30 \mathrm{~m}$, abundance was higher close to spontaneous vegetation (Fig. 2 and Table 1). Parasitoids as natural enemies of pollen beetles and aphids were less abundant close to wildflower strips at $5 \mathrm{~m}$. At $30 \mathrm{~m}$, differences between treatments were only marginally significant (Fig. 2).

In wheat fields (Fig. 3), leaf beetles and aphids were the major crop herbivores. Although leaf beetle abundance was not much influenced by strip treatments aphid abundance was significantly affected at all distances (Fig. 3 and Table 1). Close to the margin $(5 \mathrm{~m})$, the number of cereal aphids was significantly lower in the wildflower strip treatment than in the control strip whereas, at $30 \mathrm{~m}$, cereal aphid infestation was highest in the wildflower treatment. Aphid parasitism and predation were, however, not significantly different among treatments at $5 \mathrm{~m}$ and parasitism was highest in the wildflower strip treatment at $30 \mathrm{~m}$ (Fig. 3 and Table 1). Hoverflies and ladybugs were the predominant aphid predators observed in the margin strips. Hoverfly density was significantly higher in wildflower strips treatments, both 
2014: oilseed rape Within strip

$5 \mathrm{~m}$

$30 \mathrm{~m}$
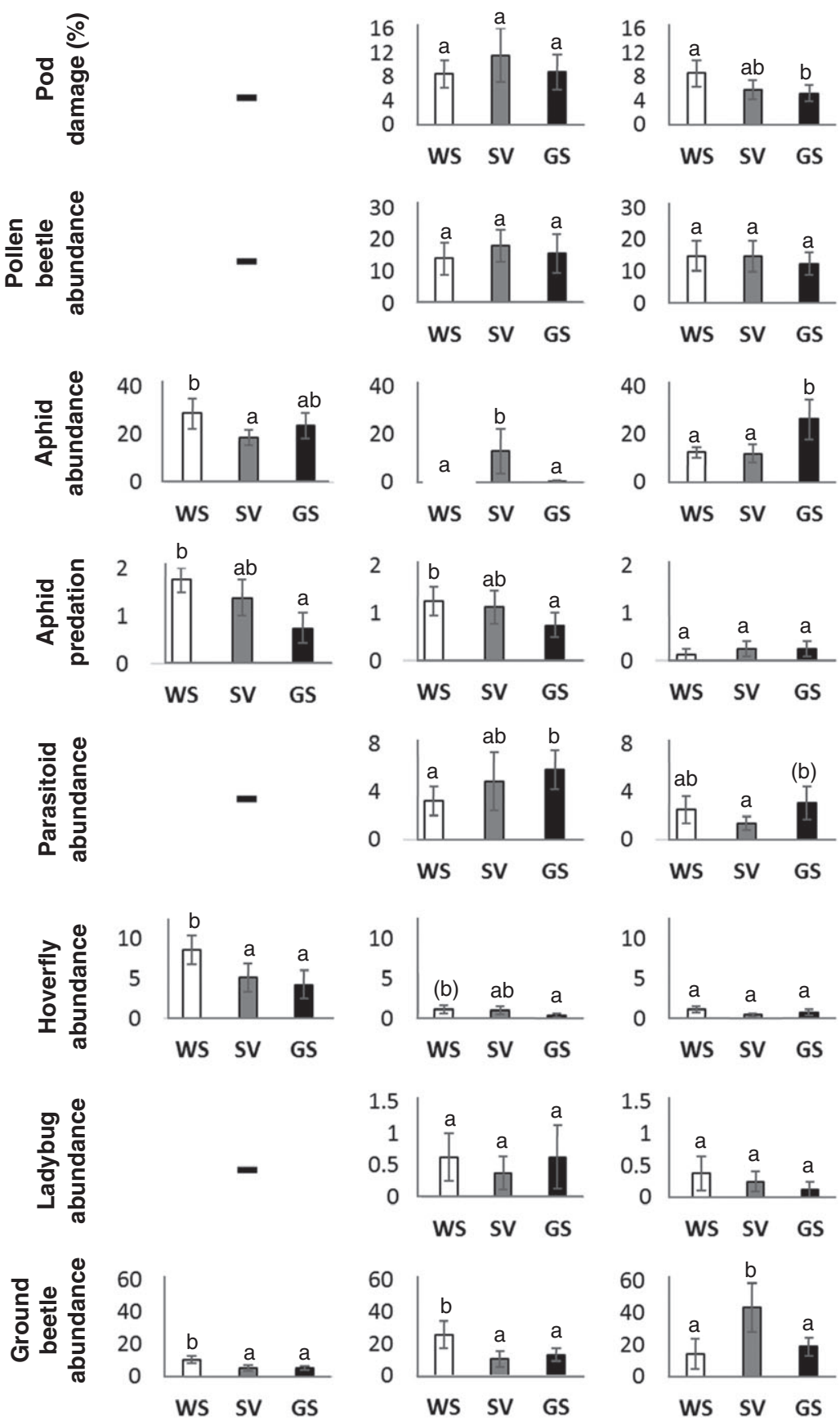

Figure 2 Oilseed rape 2014: pod damage, number of pollen beetles, aphids, parasitoids (adults), hoverflies and ladybugs (larvae and adults), aphid predation (per card), and carnivorous ground beetle abundance (per pitfall trap) within strips and at a distance of 5 and $30 \mathrm{~m}$ in the field. Abundance in the field was measured in a line of 20 oilseed rape plants per distance. WS, wildflower strip; SV, spontaneous vegetation; GS, grass strip; mean \pm SE; different lowercase letters indicate significant differences with $P<0.05$ (in parentheses: $P<0.1$ ). - , Not measured (pod damage) or almost absent (pollen beetles, parasitoids, ladybugs).

within the strips and at a distance of $5 \mathrm{~m}$, whereas no differences occurred at $30 \mathrm{~m}$ (Fig. 3 and Table 1). Ladybugs showed a significantly higher abundance in the wildflower strip treatment, although differences were not significant in the crop field (Fig. 3 and Table 1). Carnivorous ground beetles occurred in higher numbers in the control with spontaneous vegetation but, again, no significant treatment effects were observed in the field (Fig. 3).

Significant effects of insect abundance in field margins (pooled for treatments) on abundance in crop fields (herbivores and natural enemies) were found only at a distance of $5 \mathrm{~m}$ (Table 2). 
Table 1 Effect of field margin type $(d f=2)$ on crop herbivores, natural enemies, parasitism and predation within strips and at a distance of 5 and $30 \mathrm{~m}$ in the field

\begin{tabular}{llll}
\hline & $\begin{array}{l}\text { Within } \\
\text { damage (m) }\end{array}$ & $5 \mathrm{~m}$ & $30 \mathrm{~m}$ \\
\hline Oilseed rape (2014) & & & \\
Pod damage (\%) & - & $3.64^{\mathrm{NS}}$ & $7.00^{*}$ \\
Pollen beetles & - & $4.06^{\mathrm{NS}}$ & $2.22^{\mathrm{NS}}$ \\
Aphids & $16.97^{* * *}$ & $177.56^{* * *}$ & $57.32^{* * *}$ \\
Aphid predation & $11.43^{* *}$ & $7.62^{*}$ & $0.51^{\mathrm{NS}}$ \\
Parasitoids & - & $6.24^{*}$ & 5.73. \\
Hoverflies & $13.71^{* *}$ & 4.78 & $3.23^{\mathrm{NS}}$ \\
Ladybugs & - & $0.31^{\mathrm{NS}}$ & $1.05^{\mathrm{NS}}$ \\
Ground beetles & $10.63^{* *}$ & $40.72^{* * *}$ & $90.90^{* * *}$ \\
Wheat (2015) & & & \\
Leaf beetles & - & $0.39^{\mathrm{NS}}$ & 5.23. \\
Aphids & $163.57^{* * *}$ & 5.54. & $22.25^{* * *}$ \\
Aphid parasitism & - & $1.83^{\mathrm{NS}}$ & 5.70. \\
Aphid predation & $3.99^{\mathrm{NS}}$ & $1.13^{\mathrm{NS}}$ & 4.76. \\
Hoverflies & $25.54^{* * *}$ & $13.57^{* *}$ & $2.07^{\mathrm{NS}}$ \\
Ladybugs & $11.09^{* *}$ & $2.09^{\mathrm{NS}}$ & $3.24^{\mathrm{NS}}$ \\
Ground beetles & $63.92^{* * *}$ & $3.79^{\mathrm{NS}}$ & $0.98^{\mathrm{NS}}$ \\
\hline
\end{tabular}

$P<0.1$

${ }^{*} P<0.05$

${ }^{* *} P<0.01$

${ }^{* * *} P<0.001$

NS, not significant; - not measured or almost absent.

$\chi^{2}$ values and levels of significance of generalized linear mixed models

with field as random factor (d.f. $=7$ in 2014 and d.f. $=6$ in 2015).

Aphid abundance was negatively influenced by parasitoid and ladybug abundance in margin strips, indicating a positive effect of margins on aphid regulation. No correlations were obtained between aphids of margin strips and cereal aphids in crops fields, suggesting a limited exchange between margins and the field and/or a dominance of noncrop aphid species in the margins. Correlations between hoverfly abundance in field margins and in crops were not significant, whereas ladybug abundance of margins and fields was positively correlated (Table 2).

In wildflower strips adjacent to wheat fields, we found more aphids on spontaneously occurring species than on sown species (Fig. 4A). Most aphids were found on four spontaneous species, Vicia sativa (Fabaceae), Rumex obtusifolius (Polygonanceae), Galium aparine (Rubiaceae) and Cirsium vulgare (Asteraceae), and thus were not cereal aphids (Table 3). The only host of cereal aphids was wheat (Triticum aestivum) accidentally sown into the margin or emerged as a volunteer of previous crops. The three natural enemy groups analyzed were more abundant on sown plants, indicating that the selection of plant species was successful with respect to increasing regulatory potential (Fig. 4B). Parasitoids were most attracted by the sown Leucanthemum vulgare and Tanacetum vulgare, and ladybugs were most attracted by Centaurea cyanus (Asteraceae) and Dactylis glomerata (Poaceae). Hoverflies occurred on a higher number of sown than spontaneous species, although two spontaneous species, Hypochaeris radicata (Asteraceae) and Holcus lanatus (Poaceae), were the most attractive ones (Table 3).

\section{Discussion}

According to our expectations, wildflower strips showed a higher plant diversity and cover of flowering entomophilous plants used as a proxy of floral resource provisioning. The differences were stable for the two study years, demonstrating that the mixture of annual and perennial species was efficient without re-sowing and associated soil disturbance. No differences occurred between grass strips and spontaneous vegetation, indicating that grass strips allowed the development of non-sown species in the first year (Cordeau et al., 2012).

\section{Strip treatment effects on crop herbivores and natural enemies}

In agreement with other studies, sown wildflower strips harboured a greater abundance of natural enemies than spontaneous vegetation and grass strips (Pfiffner \& Wyss, 2004; Haaland et al., 2011). In particular, hoverflies occurred consistently (both years) in higher numbers in wildflower strips. Adult hoverflies are well known to rely on nectar resources (Wäckers, 2004; Fiedler et al., 2008). A better resource provisioning resulting in higher adult performance increases egg deposition and the density of aphidophagous larvae in the field (Laubertie et al., 2012). In other natural enemies, such as ground beetles and ladybugs, a positive effect of wildflower strips was observed only in the first year or in the second year, respectively. Both groups do not directly depend on floral resources. However, gut content analyses and observational studies on ladybugs have shown that adults and larvae also consume nectar and pollen contributing to fitness and predation performance (Triltsch, 1999; Ricci et al., 2005). Both ladybugs and ground beetles may have also been attracted by aphids feeding on flower stalks of entomophilous plant species representing alternative prey (Griffiths et al., 2008). A similar, clearly positive effect of entomophilous plant species on ladybug abundance has also been shown in a correlative study on spontaneous field margin vegetation in the same study area (Bischoff et al., 2016).

Inside the fields, a higher abundance in most natural enemies was observed close to wildflower strips than close to the other strip treatments at a distance of $5 \mathrm{~m}$. Higher densities of hoverflies (both years) and ground beetles (2014) were also observed in the corresponding margins. The results suggest that the attraction of natural enemies by floral resources of field margins had a positive influence on natural enemy densities in the fields and also that they are not trapped by more attractive field margin structures (associational resistance: Barbosa et al., 2009). However, the positive wildflower strip effect was not significant at a distance of $30 \mathrm{~m}$. Such a dilution of field margin resources effects on natural enemies was also observed in several other studies (Collins et al., 2002; Tylianakis et al., 2004).

In several cases, effects on crop herbivore abundance and predation corresponded to natural enemy responses to the strip treatment. In oilseed rape (first year), aphid predation was higher in wildflower strips and at a distance of $5 \mathrm{~m}$ to these strips, in accordance with a higher hoverfly and ground beetle density (significantly different from grass strips in all cases, as well as from spontaneous vegetation in hoverflies and ground beetles). Corresnonding to this higher predation and natural 
2015 : wheat

Within strip

$5 \mathrm{~m}$

$30 \mathrm{~m}$
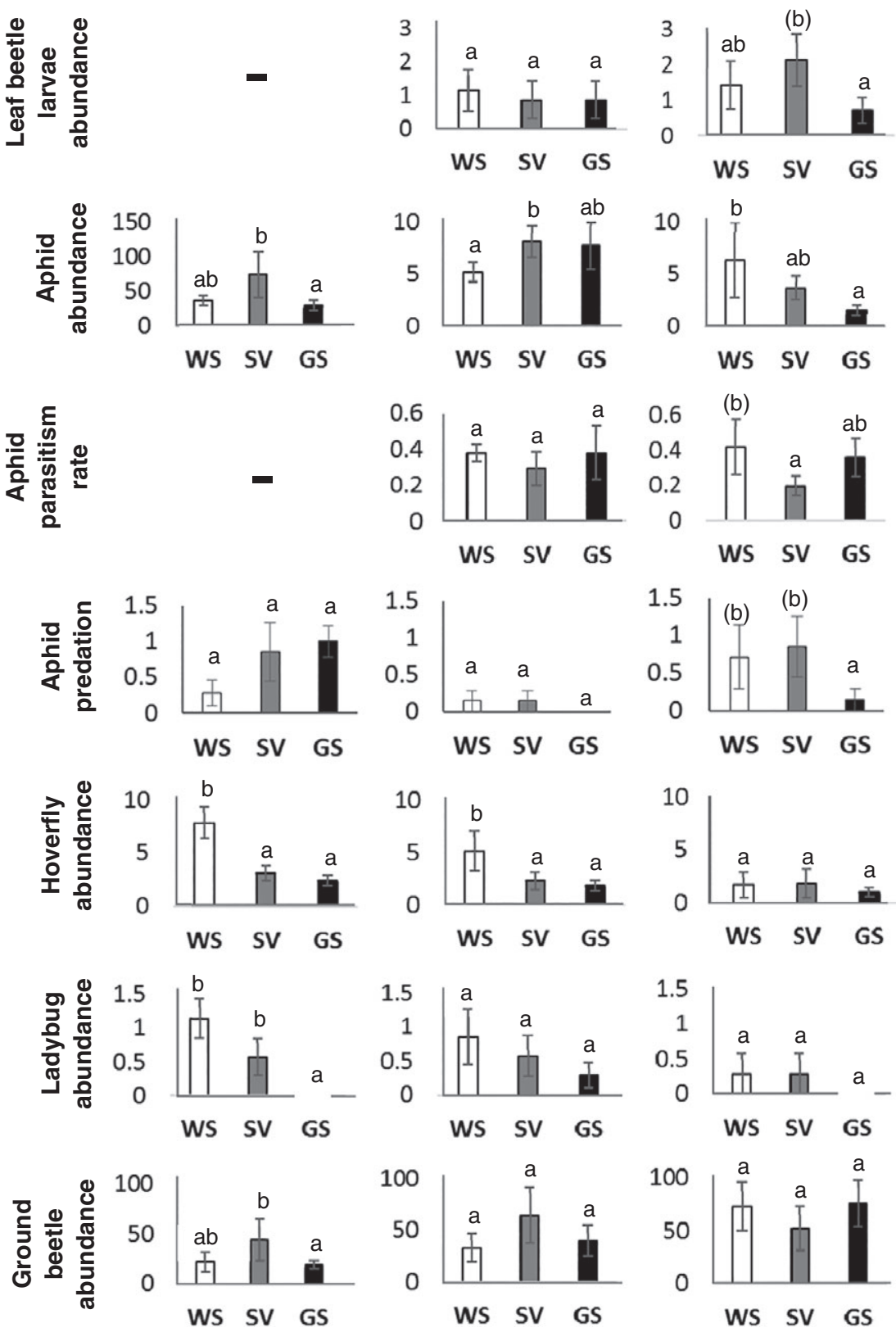

Figure 3 Winter wheat 2015, number of leaf beetle larvae, aphids, hoverflies and ladybugs (larvae and adults), aphid parasitism, aphid predation (pre card), and carnivorous ground beetle abundance in (per pitfall trap) within strips and at a distance of 5 and $30 \mathrm{~m}$ in the field. Abundance in the field was measured in a line of 50 wheat plants per distance (one tiller per plant). WS, wildflower strip; SV, spontaneous vegetation; GS, grass strip; mean \pm SE; different lowercase letters indicate significant differences with $P<0.05$ (in parentheses: $P<0.1$ ). - , Not measured.

enemy abundance, within-field aphid abundance was lower in the wildflower strip treatment than in spontaneous vegetation, although differences from the grass strip treatment were not significant. Aphid abundance in the strips did not show such pattern, although it has to be taken into account that the majority of aphids counted in the strips do not attack oilseed rape. This is one of the first studies to demonstrate a positive effect of wildflower strips on natural enemies and predation rates and, to a lesser degree, on aphid abundance in the same field experiment.
Similar results for cereal leaf beetles and natural enemies have been reported previously (Tschumi et al., 2015, 2016), although these studies compared wildflower strips with cereal strips as a control treatment.

Compared with cabbage aphids in oilseed rape, the wildflower strip effects on cereal aphid predation and parasitism in wheat (second year) were less strong but still visible. The positive effect of the wildflower strip treatment on hoverflies resulted in a higher predation, although only at a distance of $5 \mathrm{~m}$. There was no 
Table 2 Relationships between crop herbivores and natural enemies observed in field margins (explanatory variables, lines) and in wheat fields at a distance of 5 and $30 \mathrm{~m}$ from field margins (response variables, columns) in 2015

\begin{tabular}{|c|c|c|c|c|}
\hline Field margin & Cereal aphids & Hoverflies & Ladybugs & Aphid parasitism \\
\hline \multicolumn{5}{|c|}{ Field at a distance of $5 \mathrm{~m}$} \\
\hline Parasitoids & -0.214 & - & - & $0.006^{N S}$ \\
\hline Total aphids & $0.001^{\mathrm{NS}}$ & $-0.001^{N S}$ & $-0.006^{\mathrm{NS}}$ & $-0.001^{\mathrm{NS}}$ \\
\hline Hoverflies & $0.370^{N S}$ & $0.043^{\mathrm{NS}}$ & - & - \\
\hline Ladybugs & $-0.542^{*}$ & - & $0.577^{\star}$ & - \\
\hline \multicolumn{5}{|c|}{ Field at a distance of $30 \mathrm{~m}$} \\
\hline Parasitoids & $0.258^{N S}$ & - & - & $<0.001^{N S}$ \\
\hline Total aphids & $-0.001^{\mathrm{NS}}$ & $-0.001^{\mathrm{NS}}$ & $-0.019^{N S}$ & $<0.001^{N S}$ \\
\hline Hoverflies & $-0.411^{\mathrm{NS}}$ & $-0.080^{N S}$ & - & - \\
\hline Ladybugs & $0.453^{N S}$ & - & $1.382^{\mathrm{NS}}$ & - \\
\hline
\end{tabular}

. $P<0.1$.

$* P<0.05$

** $P<0.01$

**** $P<0.001$

NS, not significant ; - , not analyzed.

Estimates and significance levels of explanatory variables are presented for the generalized linear model.
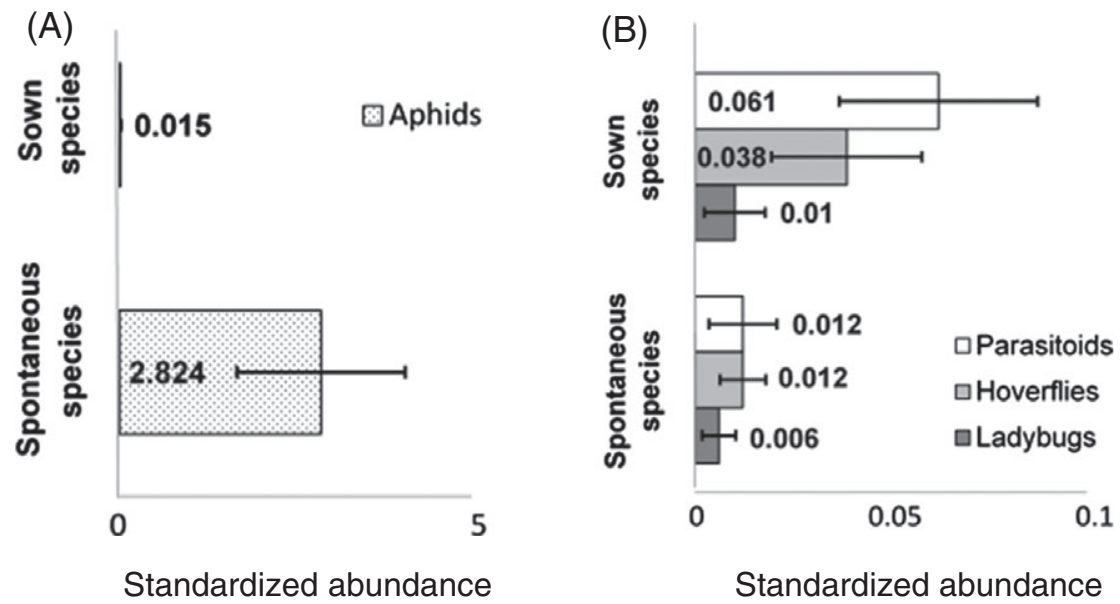

Figure 4 Attractiveness of sown and spontaneous species to herbivores and natural enemies in wildflower strips (June 2015). Standardized abundance (mean \pm SE; $n=7$ ) of (A) aphids divided by total plant cover of each group (sown, spontaneous) and (B) natural enemies divided by flower cover.

corresponding effect on cereal aphid abundance, suggesting that other factors had a stronger influence on aphid populations. Such a lack of response of crop herbivores to an increase of natural enemies and predation rates close to semi-natural habitats appears to be quite common in agro-ecosystems (Bianchi et al., 2006; Chaplin-Kramer et al., 2011; Haaland et al., 2011). For example, the proportion of noncrop areas in agricultural landscapes may increase aphid parasitism without reducing aphid densities (Le Guigo et al., 2011).

Similarly, we did not observe consistent treatment effects for other dominant crop herbivores of oilseed rape and wheat. In particular, pollen beetle density as a major oilseed rape herbivore was not influenced by the treatments. Several studies have shown that the high mobility of the beetles increases the importance of large-scale landscape structure compared with relatively small-scale features such as margin strips (Thies et al., 2003; Zaller et al., 2008). Apart from aphids, leaf beetles were the second major crop herbivores in winter wheat. By contrast to Tschumi etal. (2015), we did not find any evidence for a positive wildflower strip effect on cereal leaf beetle predation or parasitism. The magnitude of treatment effects on natural enemies may not have been sufficient to decrease leaf beetle density or the regulatory effect may have been compensated for by positive wildflower strip effects on leaf beetles. Cereal leaf beetles also feed on wild grass species and they use semi-natural habitats for overwintering (Evans et al., 2013).

\section{Interactions between strip and crop populations}

Comparisons of margin strip and field abundance depend on temporal and spatial dynamics. High mobility may increase spatial scales of interactions between field and noncrop structures beyond field margins, as already discussed for pollen beetles (Thies et al., 2003; Zaller et al., 2008). The spread from margins into the field may take some time and, after migration into the field, insect populations may decline in the margin strips (Collins et al., 2002, for ground beetles), diluting correlations between margin and field abundances. Additionally, the energetic costs of movements and the relative attractiveness of margins may 
Table 3 Standardized aphid abundance, divided by total cover of each plant species (\%), and natural enemy abundance, divided by flower cover of the respective plant species (\%), measured in wildflower strips in June 2015

\begin{tabular}{|c|c|c|c|c|c|c|}
\hline & Plant species & Aphids & Parasitoids & Hoverflies & Ladybugs & Species cover \\
\hline \multirow[t]{12}{*}{ Sown species } & Achillea millefolium & 0 & 0 & $0.14 \pm 0.05$ & 0 & $1.59 \pm 0.27$ \\
\hline & Centaurea cyanus & 0 & $0.71 \pm 0.27$ & $0.14 \pm 0.05$ & $0.14 \pm 0.05$ & $0.29 \pm 0.07$ \\
\hline & Dactylis glomerata & 0 & 0 & 0 & $0.57 \pm 0.22$ & $8.36 \pm 1.15$ \\
\hline & Echium vulgare & 0 & 0 & $0.05 \pm 0.02$ & 0 & $1.31 \pm 0.17$ \\
\hline & Heracleum sphondylium & 0 & $0.14 \pm 0.05$ & $0.09 \pm 0.03$ & 0 & $0.71 \pm 0.27$ \\
\hline & Hesperis matronalis & 0 & 0 & $0.01 \pm 0.01$ & 0 & $3.09 \pm 0.78$ \\
\hline & Leucanthemum vulgare & 0 & $2.98 \pm 1.07$ & $0.03 \pm 0.01$ & 0 & $9.59 \pm 1.24$ \\
\hline & Malva sylvestris & $0.09 \pm 0.04$ & 0 & $0.33 \pm 0.11$ & 0 & $1.72 \pm 0.19$ \\
\hline & Matricaria recutita & 0 & 0 & $0.04 \pm 0.01$ & 0 & $0.74 \pm 0.21$ \\
\hline & Tanacetum vulgare & 0 & $1.43 \pm 0.54$ & 0 & 0 & $1.87 \pm 0.29$ \\
\hline & Trifolium pratense & $0.57 \pm 0.22$ & 0 & 0 & 0 & $2.9 \pm 0.77$ \\
\hline & Trifolium repens & 0 & 0 & 0 & $0.01 \pm 0.01$ & $4.93 \pm 0.79$ \\
\hline \multirow[t]{12}{*}{ Spontaneous species } & Ammi majus & 0 & $0.09 \pm 0.04$ & 0 & 0 & $0.43 \pm 0.16$ \\
\hline & Cirsium vulgare & $11.14 \pm 2.14$ & 0 & 0 & 0 & $1.07 \pm 0.13$ \\
\hline & Euphorbia helioscopia & 0 & 0 & $0.07 \pm 0.03$ & 0 & $0.57 \pm 0.14$ \\
\hline & Galium aparine & $12.57 \pm 4.75$ & 0 & 0 & 0 & $0.51 \pm 0.11$ \\
\hline & Holcus lanatus & 0 & 0 & $1.43 \pm 0.54$ & 0 & $3.59 \pm 1.35$ \\
\hline & Hypochaeris radicata & 0 & 0 & $2.86 \pm 1.08$ & 0 & $0.46 \pm 0.07$ \\
\hline & Ranunculus repens & 0 & 0 & $0.05 \pm 0.02$ & 0 & $2.57 \pm 0.8$ \\
\hline & Raphanus raphanistrum & 0 & 0 & 0 & 0 & $0.07 \pm 0.03$ \\
\hline & Rumex obtusifolius & $15.26 \pm 4.08$ & $0.03 \pm 0.01$ & 0 & $0.05 \pm 0.02$ & $2.14 \pm 0.42$ \\
\hline & Triticum aestivum & $1.71 \pm 0.65$ & 0 & 0 & 0 & $0.29 \pm 0.07$ \\
\hline & Verbascum thapsus & $2.14 \pm 0.81$ & 0 & $0.07 \pm 0.03$ & 0 & $0.43 \pm 0.11$ \\
\hline & Vicia sativa & $22.49 \pm 6.09$ & 0 & 0 & $0.06 \pm 0.02$ & $1.66 \pm 0.33$ \\
\hline
\end{tabular}

Data are the mean \pm SE.

prevent natural enemies from moving into the field (Heimpel \& Jervis, 2005; Wanner et al., 2006). In the present study, we found a positive correlation between field (at $5 \mathrm{~m}$ ) and margin abundance of ladybugs and a negative correlation between cereal aphid field abundance and margin abundance of ladybugs. The result fits well with the observed positive effect of the wildflower strip treatment on margin abundance of ladybugs, on corresponding aphid predation and on a lower aphid abundance in the field (at $5 \mathrm{~m}$ ), suggesting a causal relationship between an increase in natural enemy and decrease in the crop herbivore population. No correlations were observed between parasitoid abundance and aphid parasitism. There is a time lag of approximately 2 weeks between parasitoid attack and mummy development (Le Guigo et al., 2011). It is thus possible that parasitoids moving from the margins into the field to attack aphids did not occur any more in the field margins when mummies were visible. Relationships between hoverfly populations of margins and fields, as well as between hoverflies and aphids, were not significant, suggesting that margins had a relatively small influence on aphid predation by hoverflies. Hoverflies are highly mobile and their field abundance may not that strongly be influenced by field margins (Wratten et al., 2003). However, the consistently higher hoverfly abundance in wildflower strips and at a distance of $5 \mathrm{~m}$ compared with grass strips and spontaneous vegetation still indicates an influence of margins on hoverfly field populations.

\section{Attractiveness of sown and spontaneous species}

In the present study, plants used in the wildflower strip mixture were more attractive for the three tested natural enemy groups (hoverflies, ladybugs and parasitoids) than the spontaneous vegetation emerging from the soil seed bank. Thus, our approach for selecting plant species that improve floral resource provisioning was successful with respect to increasing the regulatory potential of the strips. The present study highlights the importance of pollen and nectar as resources for natural enemies of crop herbivores, as also observed in other studies (Wäckers et al., 2005; Wäckers \& van Rijn, 2012). In particular, parasitoid abundance was much higher on sown plants. Parasitoids were mainly attracted by the Asteraceae species $L$. vulgare, $T$. vulgare and $C$. cyanus. The flowers of these species are known to be accessible to parasitoids that have only short mouthparts limiting access to deep flowers with long corollas (Patt et al., 1997; Williams \& Hendrix, 2008). Centaurea cyanus additionally produces extrafloral nectar easily exploitable by parasitoids (Balzan et al., 2014; Pollier et al., 2016). However, spontaneously occurring species also hosted high numbers of natural enemies. The spontaneous $H$. radicata and $H$. lanatus showed a higher hoverfly abundance than any of the sown species. Holcus lanatus is a grass species not providing any nectar. The high attractiveness may result from pollen provisioning as a second important floral resource (Laubertie et al., 2012) or from the presence of alternative hosts attracting adults for egg deposition. The role of alternative hosts was confirmed by the attraction of ladybugs on a sown grass species D. glomerata. Although sometimes feeding on pollen and nectar (Ricci et al., 2005), the high abundance of ladybugs on grass species is more likely the result of alternative host provisioning or other habitat functions (Griffiths et al., 2008). The aphids observed in high numbers on spontaneous plant species also represent alternative hosts not attacking crops. 
Cereal aphids are specialized on grass species (Poaceae) and cabbage aphids on Brassicaceae (Le Guigo et al., 2012; Evans et al., 2013), both not hosting aphids in our field margins (except for several wheat plants as contaminants). The most attractive plant species for aphids was $R$. obtusifolius, a problematic grassland weed. As a grass species, it is wind pollinated and does not provide any nectar (Cavers \& Harper, 1964).

\section{Conclusions}

In the present study, the approach aiming to increase floral resource provisioning by sowing plant species that produce a high quantity and quality of nectar and pollen was successful in attracting natural enemies of crop herbivores. For aphids, comprising the only major crop herbivore group occurring in both tested crops, a corresponding regulatory effect was confirmed down to aphid predation and aphid infestation in the field at a distance of $5 \mathrm{~m}$ from the margin strips. Such efficiency in regulation has rarely been demonstrated so far because most studies on wildflower strips have been limited to natural enemies or have not shown any significant effect on herbivores (Haaland et al., 2011). The negative correlations between natural enemy abundance in margin strips and aphid abundance in the field support the hypothesis of a causal relationship between natural enemy attraction by floral resources of the margins and biological control. However, several major crop herbivores did not respond to our treatments despite an increase of natural enemy abundance in wildflower strips. Such an absence of crop herbivore response suggests that factors other than natural enemy abundance determine herbivore population dynamics (Thies et al., 2005; Chaplin-Kramer et al., 2011; Haaland et al., 2011). Further research is needed on regulatory effects down to the crop herbivore level, as well as on natural enemy movements between fields and margins, in order to evaluate the potential contribution of field margin management to the control of crop herbivores in the field.

Grass strips did not improve control service of margins. Natural enemy densities were generally lower than in wildflower strips and sometimes even lower than in spontaneous vegetation with a corresponding absence of crop herbivore regulation. The more positive evaluation of grass strips in other studies (Collins et al., 2002; Al Hassan et al., 2013) was probably the result of the use of a complete absence of margin strips as a control. The use of less attractive control treatments (absence of vegetation, crop strips) may also explain the stronger effects of wildflower strips on crop herbivore regulation that were occasionally observed in other studies (Haaland etal., 2011; Tschumi et al., 2015; Hatt et al., 2017). However, we consider that an efficient ecological engineering approach such as wildflower strip sowing needs to demonstrate a better regulatory effect than spontaneous vegetation not requiring any sowing or preparation costs.

\section{Acknowledgements}

We thank E. Chenu and F. Braud for their technical assistance, as well as T. Sollet and S. Le Barazer for their help in the field. We also thank all of the farmers who participated in the present study for their hospitality and providing information.
The project was funded by the French National Research Agency (ANR-12-AGRO-0006, 'PEERLESS') and the chair Ecologically Intensive Agriculture (AEI).

\section{Supporting information}

Additional supporting information may be found online in the Supporting Information section at the end of the article.

Table S1. Sown species in the wildflower strip treatment.

\section{References}

Al Hassan, D., Georgelin, E., Delattre, T., Burel, F., Plantegenest, M., Kindlmann, P. \& Butet, A. (2013) Does the presence of grassy strips and landscape grain affect the spatial distribution of aphids and their carabid predators? Agricultural and Forest Entomology, 15, 24-33.

Araj, S.-E. \& Wratten, S.D. (2015) Comparing existing weeds and commonly used insectary plants as floral resources for a parasitoid. Biological Control, 81, 15-20.

Balmer, O., Géneau, C.E., Belz, E. et al. (2014) Wildflower companion plants increase pest parasitation and yield in cabbage fields: experimental demonstration and call for caution. Biological Control, 76, 19-27.

Balzan, M.V., Bocci, G. \& Moonen, A.-C. (2014) Augmenting flower trait diversity in wildflower strips to optimise the conservation of arthropod functional groups for multiple agroecosystem services. Journal of Insect Conservation, 18, 713-728.

Barbosa, P., Hines, J., Kaplan, I., Martinson, H., Szczepaniec, A. \& Szendrei, Z. (2009) Associational resistance and associational susceptibility: having right or wrong neighbors. Annual Review of Ecology, Evolution, and Systematics, 40, 1-20.

Bianchi, F.J.J.A., Booij, C.J.H. \& Tscharntke, T. (2006) Sustainable pest regulation in agricultural landscapes: a review on landscape composition, biodiversity and natural pest control. Proceedings of the Royal Society of London B: Biological Sciences, 273, 1715-1727.

Bischoff, A., Pollier, A., Lamarre, E. et al. (2016) Effects of spontaneous field margin vegetation and surrounding landscape on Brassica oleracea crop herbivory. Agriculture, Ecosystems and Environment, 223, $135-143$.

Blaauw, B.R. \& Isaacs, R. (2012) Larger wildflower plantings increase natural enemy density, diversity, and biological control of sentinel prey, without increasing herbivore density. Ecological Entomology, 37, 386-394.

Braun-Blanquet, J. (1964) Pflansensoziologie, 3rd edn. Springer, Austria.

Cavers, P.B. \& Harper, J.L. (1964) Rumex obtusifolius L. and R. crispus L. Journal of Ecology, 52, 737-766.

Chaplin-Kramer, R., O’Rourke, M.E., Blitzer, E.J. \& Kremen, C. (2011) A meta-analysis of crop pest and natural enemy response to landscape complexity. Ecology Letters, 14, 922-932.

Collins, K.L., Boatman, N.D., Wilcox, A., Holland, J.M. \& Chaney, K. (2002) Influence of beetle banks on cereal aphid predation in winter wheat. Agriculture, Ecosystems and Environment, 93, 337-350.

Cordeau, S., Petit, S., Reboud, X. \& Chauvel, B. (2012) Sown grass strips harbour high weed diversity but decrease weed richness in adjacent crops. Weed Research, 52, 88-97.

Daamgard, C. (2014) Estimating mean plant cover from different types of cover data: a coherent statistical framework. Ecosphere, 5, 1-7.

Dassou, A.G. \& Tixier, P. (2016) Response of pest control by generalist predators to local-scale plant diversity: a meta-analysis. Ecology and Evolution, 6, 1143-1153. 
Evans, E.W., Carlile, N.R., Innes, M.B. \& Pitigala, N. (2013) Warm springs reduce parasitism of the cereal leaf beetle through phenological mismatch. Journal of Applied Entomology, 137, 383-391.

Fiedler, A.K., Landis, D.A. \& Wratten, S.D. (2008) Maximizing ecosystem services from conservation biological control: the role of habitat management. Biological Control, Conservation Biological Control, 45, 254-271.

Griffiths, G.J.K., Holland, J.M., Bailey, A. \& Thomas, M.B. (2008) Efficacy and economics of shelter habitats for conservation biological control. Biological Control, Conservation Biological Control, 45, 200-209.

Gurr, G.M., Wratten, S.D. \& Luna, J.M. (2003) Multi-function agricultural biodiversity: pest management and other benefits. Basic and Applied Ecology, 4, 107-116.

Haaland, C., Naisbit, R.E. \& Bersier, L.-F. (2011) Sown wildflower strips for insect conservation: a review. Insect Conservation and Diversity, 4, 60-80.

Hatt, S., Lopes, T., Boeraeve, F., Chen, J. \& Francis, F. (2017) Pest regulation and support of natural enemies in agriculture: experimental evidence of within field wildflower strips. Ecological Engineering, 98, 240-245.

Heil, M. (2015) Extrafloral nectar at the plant-insect interface: a spotlight on chemical ecology, phenotypic plasticity, and food webs. Annual Review of Entomology, 60, 213-232.

Heimpel, G.E. \& Jervis, M.A. (2005) Does Floral Nectar Improve Biological Control by Parasitoids. Cambridge University Press, U.K.

Hicks, D.M., Ouvrard, P., Baldock, K.C.R. et al. (2016) Food for pollinators: quantifying the nectar and pollen resources of urban flower meadows. PLOS ONE, 11, e0158117.

Jamont, M., Crépellière, S. \& Jaloux, B. (2013) Effect of extrafloral nectar provisioning on the performance of the adult parasitoid Diaeretiella rapae. Biological Control, 65, 271-277.

Klotz, S., Kühn, I. \& Durka, W. (2002) Database on Biological and Ecological Traits on the Flora of Germany - Schriftenreihe für Vegetationskunde 38. Bundesamt für Naturschutz, Germany.

Koji, S., Khan, Z.R. \& Midega, C.A.O. (2007) Field boundaries of Panicum maximum as a reservoir for predators and a sink for Chilo partellus. Journal of Applied Entomology, 131, 186-196.

Landis, D.A., Wratten, S.D. \& Gurr, G.M. (2000) Habitat management to conserve natural enemies of arthropod pests in agriculture. Annиal Review of Entomology, 45, 175-201.

Laubertie, E.A., Wratten, S.D. \& Hemptinne, J.-L. (2012) The contribution of potential beneficial insectary plant species to adult hoverfly (Diptera: Syrphidae) fitness. Biological Control, 61, 1-6.

Le Guigo, P., Qu, Y. \& Le Corff, J. (2011) Plant-mediated effects on a toxin-sequestering aphid and its endoparasitoid. Basic and Applied Ecology, 12, 72-79.

Le Guigo, P., Rolier, A. \& Le Corff, J. (2012) Plant neighborhood influences colonization of Brassicaceae by specialist and generalist aphids. Oecologia, 169, 753-761.

Marshall, E.J.P. \& Moonen, A.C. (2002) Field margins in northern Europe: their functions and interactions with agriculture. Agriculture, Ecosystems and Environment, 89, 5-21.

Patt, J.M., Hamilton, G.C. \& Lashomb, J.H. (1997) Foraging success of parasitoid wasps on flowers: interplay of insect morphology, floral architecture and searching behavior. Entomologia Experimentalis et Applicata, 83, 21-30.

Pfiffner, L. \& Wyss, E. (2004) Use of sown wildflower strips to enhance natural enemies of agricultural pests. Ecological Engineering for Pest Management (ed. by G. M. Gurr, S. D. Wratten and M. A. Altieri), pp. 167-188. CABI-Publishing, Australia.

Pollier, A., Dosdat, S., Tricault, Y., Bischoff, A., Plantegenest, M. \& Jaloux, B. (2016) Using the stable isotope marker ${ }^{13} \mathrm{C}$ to study extrafloral nectar uptake by parasitoids under controlled conditions and in the field. Entomologia Experimentalis et Applicata, 161, $131-140$

R Development Core Team (2015) R: A Language and Environment for Statistical Computing. R Foundation for Statistical Computing, Austria.

Ricci, C., Ponti, L. \& Pires, A. (2005) Migratory flight and pre-diapause feeding of Coccinella septempunctata (Coleoptera) adults in agricultural and mountain eco-systems of Central Italy. European Journal of Entomology, 102, 531-538.

Roschewitz, I., Hücker, M., Tscharntke, T. \& Thies, C. (2005) The influence of landscape context and farming practices on parasitism of cereal aphids. Agriculture, Ecosystems and Environment, 108, $218-227$.

Thies, C., Steffan-Dewenter, I. \& Tscharntke, T. (2003) Effects of landscape context on herbivory and parasitism at different spatial scales. Oikos, 101, 18-25.

Thies, C., Roschewitz, I. \& Tscharntke, T. (2005) The landscape context of cereal aphid-parasitoid interactions. Proceedings of the Royal Society of London B: Biological Sciences, 272, 203-210.

Triltsch, H. (1999) Food remains in the guts of Coccinella septempunctata (Coleoptera: Coccinellidae) adults and larvae. European Journal of Entomology, 96, 355-364.

Tschumi, M., Albrecht, M., Entling, M.H. \& Jacot, K. (2015) High effectiveness of tailored flower strips in reducing pests and crop plant damage. Proceedings of the Royal Society of London B: Biological Sciences, 282, 20151369.

Tschumi, M., Albrecht, M., Bärtschi, C., Collatz, J., Entling, M.H. \& Jacot, K. (2016) Perennial, species-rich wildflower strips enhance pest control and crop yield. Agriculture, Ecosystems and Environment, 220, 97-103.

Tylianakis, J.M., Didham, R.K. \& Wratten, S.D. (2004) Improved fitness of aphid parasitoids receiving resource subsidies. Ecology, 85, $658-666$.

Wäckers, F. (2004) Assessing the suitability of flowering herbs as parasitoid food sources: flower attractiveness and nectar accessibility. Biological Control, 29, 307-314

Wäckers, F.L. \& van Rijn, P.C.J. (2012) Pick and mix: selecting flowering plants to meet the requirements of target biological control insects. Biodiversity and Insect Pests (ed. by G. M. Gurr, S. D. Wratten, W. E. Snyder and D. M. Y. Read), pp. 139-165. John Wiley \& Sons, Ltd, Chichester, U.K.

Wäckers, F.L., van Rijn, P.C.J. \& Bruin, J. (2005) Plant-Provided Food for Carnivorous Insects: A Protective Mutualism and its Applications. Cambridge University Press, Cambridge, U.K.

Wanner, H., Gu, H., Hattendorf, B., Günther, D. \& Dorn, S. (2006) Using the stable isotope marker ${ }^{44} \mathrm{Ca}$ to study dispersal and host-foraging activity in parasitoids: stable isotope marking of parasitoids. Journal of Applied Ecology, 43, 1031-1039.

Williams, L. \& Hendrix, D.L. (2008) Comparing different floral resources on the longevity of a parasitic wasp. Agricultural and Forest Entomology, 10, 23-28.

Winkler, K., Wäckers, F.L., Kaufman, L.V., Larraz, V. \& van Lenteren, J.C. (2009) Nectar exploitation by herbivores and their parasitoids is a function of flower species and relative humidity. Biological Control, 50, 299-306.

Wratten, S.D., Bowie, M.H., Hickman, J.M., Evans, A.M., Sedcole, J.R. \& Tylianakis, J.M. (2003) Field boundaries as barriers to movement of hover flies (Diptera: Syrphidae) in cultivated land. Oecologia, 134, 605-611.

Zaller, J.G., Moser, D., Drapela, T., Schmöger, C. \& Frank, T. (2008) Insect pests in winter oilseed rape affected by field and landscape characteristics. Basic and Applied Ecology, 9, 682-690.

Accepted 6 November 2018

First published online 29 November 2018 